\title{
BRCA1 Biallelic Inactivation
}

National Cancer Institute

\section{Source}

National Cancer Institute. BRCA1 Biallelic Inactivation. NCI Thesaurus. Code C142121.

The presence of mutations in both alleles of the BRCA1 gene that either lead to loss of expression of the BRCA1 protein or result in the translation of an inactive BRCA1 protein. 